\title{
Gate Review as a Project Management Tool for Optimal Outcome A Hypothetical Case Study
}

\section{Roderick Facey' ${ }^{1}$ and Charles Ouseph ${ }^{2 *}$}

${ }^{1}$ Vice President, Gemini Corporation, Calgary, Alberta T2P 3C8, Canada

${ }^{2}$ Technical Specialist, Gemini Corporation, Sherwood Park, Alberta T8H 0J4, Canada

\begin{abstract}
The objective of this white paper is to explain the best way of using gate review as an effective tool for the optimal management of projects. Presented here are lessons learned during the past many years of managing/ coordinating million and billion dollar projects across North America. In all significant projects, a gate review is generally conducted using customized check lists to generate a qualitative or semi-quantitative information on the many levels of risks associated with each of the potential hazards and operability problems that could adversely impact the allocated budget, raise liability concerns, and delay in completing the project. The check lists serve as an event sieve incorporating all probable situations that may occur during the life of the project, and thereby making the gate review process meaningful and targeted in developing a risk matrix that quantify the likelihood and severity of a bad event happening. Thus having a reliable risk matrix brings substantial savings in completing the project on time, in safeguarding HS\&E in the workplace \& surrounding communities, and would bring down future operating costs in many ways from insurance premiums to O\&M costs. Thus this white paper summarizes some of the best means to conduct an enhanced gate review prior to field implementing a project for achieving maximum benefits.
\end{abstract}

\section{Acronyms}

$\mathrm{CPM}=$ Critical Path Method; DBM = Design Basis Memorandum; EDS = Engineering Design Specification; $\mathrm{EPCM}=$ Engineering, Procurement, and Construction Management; HAZOP = HAZard and OPerability analysis (study); HS\&E = Health, Safety \& Environment; IFC = Issued For Construction; LOPA = Layers Of Protection Analysis; $\mathrm{O} \& \mathrm{M}=$ Operation \& Maintenance; $\mathrm{P} \& \mathrm{ID}=$ Process \& Instrumentation Diagram; PERT $=$ Program Evaluation and Review Technique; PFD $=$ Process Flow Diagram; PM $=$ Project Manager; RFP $=$ Request For Proposal; SIL $=$ Safety Integrity Level; SOP = Standard Operating Procedure; $\mathrm{SPL}=$ Safety Protection Layer; $\mathrm{TF}=$ Tolerable Frequency; WHMIS $=$ Workplace Hazardous Materials Information System

\section{Introduction}

This paper summarizes a recommended procedure for conducting a checklist review (i.e., gate review) on complex projects in a way that realizes the most benefits to all stakeholders in the project. The purpose of a gate review is to evaluate design basis, technology used, implementation plans, the construction drawings and associated documents, the level of compliance with standards and codes, and ultimately to confirm the following:

- Is the project based on established design practices and engineering standards in order to ensure safety, reliability and technical performance.

- Will the process after completion of construction operate as planned and whether all the processes are likely to meet its intended level of output performance.

- Is the design in compliance of all applicable standards, professional obligations and legislation.

- Are the construction drawings and documents complete to the level of IFC quality and suitability for issue and construction.

\section{Methodology}

The evaluation of projects including drawings and documents require developing customized checklists by incorporating relevant parameters that are important to assess the suitability of each stage from conceptual phase and design basis memorandum (DBM) to the point of commissioning. The checklist is also used to identify those missing deliverables required at the various stages to avoid unnecessary delays in project execution, to ensure that all stages meet the minimum standards and codes, and also to reduce potential financial losses/ risks/ liability/EH\&S concerns. The gate review generally include an evaluation of process deliverables which may include structural \& architectural items, mechanical \& piping layout, electrical \& instrumentation set-up, geotechnical \& building plans, and suitability of IFC drawings. Depending on the project, there may be other gates for review.

The efficacy of a gate review depends on how well customized are all the check lists. That requires a thorough understanding of the goals of the project. Accordingly a team of professionals with relevant training and hands-on experience from different disciplines have to be assembled. As an aid in developing check lists, a flow diagram incorporating all the tasks and phases involved in completing the project from concept to commissioning be developed and reviewed. These horizontally connected blocks have to be vertically segregated into various disciplines which for example may include: mechanical/ piping, electrical/ instrumentation, chemical/process, civil/structural, geotechnical/foundation, and compliance with minimum design standards \& codes.

Separate check lists have to be developed for each category of the principal tasks under each discipline. In order for these check lists to evaluate all probabilities in each sub-task, it is important for the team member developing check lists to have prior hands-on experience in implementing similar projects. For each component parameter in the

${ }^{*}$ Corresponding author: Dr. Charles Ouseph, P.E.Technical Specialist, Gemin Corporation, Sherwood Park, Alberta T8H 0J4, Canada, Tel: (780)416-1112; Fax: (780)416-1229; E-mail: couseph@geminicorp.ca

Received June 05, 2012; Accepted June 22, 2012; Published June 25, 2012

Citation: Facey R, Ouseph C (2012) Gate Review as a Project Management Tool for Optimal Outcome A Hypothetical Case Study. J Civil Environ Eng 2:119. doi:10.4172/2165-784X.1000119

Copyright: ( 2012 Facey R, et al. This is an open-access article distributed under the terms of the Creative Commons Attribution License, which permits unrestricted use, distribution, and reproduction in any medium, provided the original author and source are credited. 
check list, a weight factor has to be assigned depending on how critical that component is for the project. These assigned factors may be a numerical number (like 0.1 to 1.0 or 1 to 10 or 10 to 100 ). For those items MISSING or kept on HOLD in the project implementation plan have to be assembled and a separate evaluation be made to determine how critical are they and how soon corrective action can be taken to ensure completion of the project well on time and within budget.

The second factor across in the check list in assigning a numerical score depends on how well each of the particular check list line item is addressed in the proposed project implementation plan. This weight factor being subjective as before, the team member developing and using the check list is to have prior experience in the field implementation of similar projects. The level of adequacy in evaluating the various components in a proposed project implementation plan could be rated or graded in many ways. Following is an example of such a grading: A score of 1 (or 10 to 20) for a parameter that is marginally addressed in the data package could be rated as POOR, similarly a score of 2 (or 30 to 40) could be rated as FAIR, a score of 3 (or 50 to 60) for AVERAGE, a value of 4 (or 70 to 80) for ABOVE AVERAGE, and a value of 5 (or 90 to 100) to represent EXCELLENCE.

\section{Details of Gate Review Process}

As part of the Gate Scoring Process, having a base line cost-benefit analysis would help in identifying the best options to commence the conceptual stage and to have the design basis memorandum (DBM) for follow-up work. The above analysis would also help in developing a better business model and cost estimate. Also as part of engineering, procurement, and construction management (EPCM), it would be beneficial for the project to have each budget line item tied to specific tasks with schedules and costs so that the data can be continuously monitored using the PERT chart which is to be adjusted with actual times as the project progresses. The PERT is intended for large scale complex projects with a high degree of interdependent tasks, some of which requires a series of activities to be performed sequentially while others performed in parallel alongside with other activities. The PERT also helps to make optimal decision during the many intermediate steps and also helps to reduce both time and cost required to complete the project. It also helps to deal with many of the unexpected situations that may occur during the many stages of EPCM beginning from the conceptual \& DBM phases to commissioning/turn-key stage. The absence of a plan B to overcome such unplanned situations cause significant bottlenecks during the implementation of critical steps in the project, and that would adversely impact the sequential milestones, schedules, and allocated budget. It is important to have such critical steps analyzed by CPM which invariably will have alternate pathways (plan B) built-in to ensure that such vital steps in the project proceed as planned. For an effective scoring model, the checklist should evaluate whether the various disciplines and stages of project implementation plan have studies completed to address contingencies and to help reduce risks including potential liability in the various phases of project implementation. Such studies may include to name a few, one or more of the following: CPM, HAZOP, LOPA, SIL assessment, SPLs, and details of emergency shutdown keys. If some of the "what if" situations are not properly addressed in the early stages, the same would significantly impede sequentially the milestone schedules, timelines, and budget.

Another recommendation is to consider structural changes in the check list scoring system where the check lists happen to apply arbitrarily across all projects using one or two weight factors only, like say a 5 or 10. If that were the case, then it implies that the one or two quantifying numbers are a good fit for all items being scored in all projects and in all situations, and that obviously cannot be true. While the above methodology simplifies the scoring process, it only provides a marginally qualitative answer. But the same could be improved to the next level of accuracy by making the scoring process more detailed and more quantifying. By having additional weighing factors that more accurately reflect the relative importance of the particular item being scored in implementing the project, the scoring and ranking process both achieve a much higher level of confidence.

Depending on the level of reliability desired in the subjective estimation, a checklist can be structured in many ways. The reliability also depends on having the most appropriate parameters in the particular discipline included in the checklist and how best the same are addressed in the proposed project implementation plan in assigning the score. The level of reliability in the scoring process that come out of the application of check lists also depends on the experience of the person who developed and used the check lists in the scoring process.

\section{Construction Drawing Package}

In the context of managing a complex project, the project manager (PM) often has to evaluate a construction drawing package. If the drawing package comes without the process flow diagram (PFD), it does not provide the minimum design details that are necessary to ensure compliance with the codes and standards. The absence of adequate design details negatively impact the project in establishing at least the following:

- Computation of mass and energy balance

- Developing standard operating procedures for the optimal operation of process in all modes

- Identifying and evaluating potential risks to facility and process operators

A construction drawing package without the equipment data sheet negatively impacts the project in realizing at least the following:

- Lacks information on the reliability in terms of accuracy and precision of data generated by each equipment,

- With equipment data sheet missing, identifying the location of a particular equipment in the construction drawings becomes difficult and that impacts the construction phase in the field,

- Supply chain management becomes difficult with respect to procuring and operating by the owner, contractor, and equipment supplier/manufacturer

A construction drawing package without details of the shut-down key could bring significant risks to both the project and staff therein. Therefore the drawing package should include a control philosophy statement to deal with the following modes of operation such as normal, start-up, routine shut-down, emergency situations, and first commissioning.

The construction drawing package without the instrument index negatively impacts the project in the following:

- The drawings become less usable in the field implementation of the project without knowing what instrument goes where in the blue prints,

- Makes it difficult to evaluate the reliability in terms of accuracy and precision with respect to the data generated by instruments,

- Maintenance and or periodic re-calibration of instruments as recommended by manufacturers. 
In summary, the above are some of the items that often gets missed or inadequately addressed, but they all have to be included as part of the construction package to ensure the optimal management of the project and to facilitate the following:

- All missing information, incomplete details, and HOLD items have to be assembled and corrective actions taken as soon as possible as part of the construction drawing package to receive the required regulatory approval for initiating construction process,

- To receive competitive bidding from reputable construction contractors,

- Minimize potential delays in the timely completion of construction \& commissioning,

- Contractors, vendors, manufacturers, and suppliers would remain identified and responsible, for both the integrity and proper operation of equipment, instruments, buildings, and the like for a period of time as agreed beforehand under the terms of the contract and or project schedule,

- Reduce risk and potential liability thereof in awarding contracts and that helps in the proper completion of construction on time and within budget,

- Helps to achieve expected level of performance in all of the systems during facility operations,

- Enhance cost efficiency in construction, increase operational flexibility, and reduce down time,

- In developing a dedicated operation and maintenance (O\&M) manual to ensure optimal facility operations.

\section{Causes of Potential Hazards and Operability Problems}

Where a scenario is too complex or the consequences are too severe for the HAZOP team to make a sound enough judgment, LOPA is applied to assess the adequacy of existing or proposed layer of protection against various accident scenarios. The inputs to the LOPA study in combination with SIL may include process deviation, causes, risk levels, and safeguards identified during the HAZOP studies. The SIL/LOPA assessment leads to recommended Safety Protection Layers (SPLs) / safeguards in place and if there still continues to be residual risk causing hazards and operability problems exceeding tolerable frequency (TF), then further risk reduction is required. Since complex projects involve multiple processes, equipment, recording instruments, and so on, all supposed to consistently function as intended in the design, a deviation from the design intent could occur by human error, equipment failure, and or external events. Once the credible causes of deviation are uncovered as part of HAZOP and or through other equivalent form of study, then additional safeguards are to be put in place. This includes engineering design modifications, revised written procedures in operating the system, and or the system redesigned to detect and give early warning when a deviation occurs. Analysis of hazards requires an assessment of consequence of one or more failures involving engineering design, equipment malfunction, human error, external events, or administrative controls. Also it is important to consider multiple failures happening simultaneously in order to establish whether any of the safeguards will actually function and mitigate in the event of such an occurrence.

\section{Design Basis Memorandum (DBM) Stage}

The design basis should consider all aspects of the project implementation plan and is an essential part of the scoring. The scoring and ranking process may be further enhanced by incorporating a preliminary risk assessment with emphasis on the liability implications both at the micro and macroeconomic scale which together would have a bearing on the financial health of the business going forward.

As part of the risk evaluation, both HAZOP and HS\&E studies are important items with financial implications. Therefore they both have to be considered in the check list scoring process. A HAZOP study identifies process hazards and operability issues related to the various project implementation stages starting with the conceptual and DBM phases. The focus of HAZOP study is to identify potential accidents and emergency situations in facility operations, all of which may impact HS\&E at the workplace and surrounding communities as well as the financial health of the business. The inputs in HAZOP study include situations outside of routine operations and how the same changes the risk matrix. The above are factors likely to adversely impact the reputation of business and may cause economic loss. The results of HAZOP study generally include the risk ranking of each identified cause and also helps to come up with recommendations in the form of safeguards to lower the risk. If the total score for the checklists for one or more stages is less than the acceptable score for the Gate, there may be only just enough time to correct the deficiencies or run the risk of significant delays in completing the project which may cause the withdrawal of funds for the project to proceed.

After the HAZOPO study, further risk reduction is achieved by conducting an assessment of SIL, adequacy of SPLs, LOPA, and updating the PERT chart as the project progresses. If the total of frequency of all causes is less than the tolerable frequency, the integrated study may be considered complete.

The HAZOP study is integrated with safety integrity level (SIL) study for each of the identified node. Each of the process parameter and other deviations when applied to each node identifies the associated hazards. The resulting risk score based on the consequences are recorded as per the risk matrix. When an adequate number of independent layers of protection are identified to reduce the risk to a tolerable level, then no further safeguards are warranted. If the safeguards are not reducing the risk to an acceptable level, then more actions are developed and applied to reduce the risk to an acceptable level.

\section{Engineering Design Specification (EDS) Stage}

An important consideration in the implementation of any project execution plan is how the project interfaces with surrounding infrastructures and adjoining communities. If not already considered, it is important for the Gate Review Team to give attention on the social, political, regulatory process, and to identify a mechanism towards establishing communication with all stakeholders and also to help achieve some level of acceptance of the project on hand by surrounding communities. Since there are far too many "what if" questions and situations inherent in the above noted factors with no clear cut answers, they all carry anywhere from minimal to significant risk on project schedules/time lines.

Since deviations and deficiencies are almost always identified during the start-up phase, they are routinely lumped together and are customarily called by industry practice the punch list. These in most cases are minor and get corrected in the start-up phase. But at times, some of the above factors can have significant adverse impact in the completion of the project and therefore on the business, it may be worth another look to evaluate whether the scoring model has taken into consideration at least some of the above factors in the checklist scoring and ranking process. 
Commissioning Stage: It is important to have the checklist scoring consider the final equipment testing which is generally the "acceptance testing". Apart from the customary warranty/guarantee of the manufacturer and or contractor as the case may be with respect to major equipment, the RFP based on which the contract is awarded generally requires the contractor to have as part of the acceptance testing the satisfactory operation of the system non-stop for an extended period of time like say, 5 days (120 hrs) or any other duration as agreed in the contract. As part of the commissioning process, the contractor is generally required to provide training to select number of employees in the routine maintenance and operation of the equipment. These are factors important enough to be considered in the scoring model to reach the correct ranking. Based on construction practices and commissioning operations, there would generally be many deviations from the standard specifications. These deviations are corrected by the contractor usually with no financial implications during the commissioning/ start-up phase. In the same start-up phase, it is a good opportunity for the DBM, EDS, checklist scoring staff, and other stakeholders to be physically present and work with the contractor during the start-up days and often that would likely find areas where operational flexibility and cost efficiency could be enhanced at minimal expenditures or at some additional cost if the project manager and or owner agrees to accept that extra cost. Apart from that, it is necessary for some of the project staff to be present during the start-up phase for the physical verification of all deliverables and to ensure compliance with the terms of the contract. Since many of the above factors can have significant impact on the project as a whole, it is important to evaluate whether the scoring model has taken into consideration the above factors in the checklist scoring and ranking process.

\section{Completion Gate}

The many steps as noted before are important factors to be considered in completing the checklist score card in order to produce a better ranking in the gate scoring summary. As part of the commissioning process, the general contractor usually test-run separately some of the sub-systems for performance to ensure that parts of all deliverables meet the terms of the contract. Finally the whole system undergoes test as a total system and operates trouble free and delivers performance as stated in the contract for a continuous/non-stop period of time as per the contract, and then in most situations, the same qualify as acceptance tests. Subject to other caveats in the terms of the contract like warranty of proper operability of equipments and guarantee of performance for a defined period of time, the contractor after having demonstrated full compliance of the terms of the contract usually hands over the system to the owner-operator or others responsible for the continued operation of the system.
The project generally is not finished unless a provision is somewhere out there to include the remaining items such as completion of an O\&M manual, staff training as required under WHMIS, obtaining regulatory approvals (i.e., continued operation require preparation of permit applications often involving multiple regulatory agencies), and the like. They all should be part of the commissioning process unless the same are included as part of another project or are excluded under the terms of the current contract.

\section{Construction Gate}

If all of the steps in the project were implemented as per schedule, then it is unlikely to have ever a need for the hard stop gate, but if it becomes necessary, the same would have adverse business/financial implications in proportion to the duration of the hard stop. If a hard stop gate becomes necessary, then the gate review process at least in part failed to meet the primary objective in the optimal management of the project. The construction mobilization gate is both a critical milestone and a timeline where contractors must have all the approved deliverables in place at least few weeks prior to the proposed start-up date of work commencement.

\section{Examples of Gate Review Process}

For illustrative purposes, here are some examples of checklists prepared for conducting the gate review in our hypothetical facility and are shown in Table 1 and Table 2.

The table 3 details the levels of criticalness of certain missing documents in the information package. From an examination of the table below, it can be seen that a majority of the documents are critical at the construction stage in order to avoid delays related to contractor bidding, procurement, fabrication, construction, installation and startup.

\section{Incomplete Construction Drawings and Documents}

For illustrative purpose, the following are some of the often overlooked but significant items which may be either totally missing or inadequately addressed:

- Process P\&IDs - HOLD for missing vendor data \& information

- Utility P\&IDs - Hold for HAZOP

- Line List HOLD - for line sizing \& pressure safety valve (PSV) sizing

- Instrument Data Sheets not of construction quality, missing vendor information

- Equipment Index - HOLD for missing vendor data \& information

\begin{tabular}{|c|c|c|c|c|c|c|c|c|c|}
\hline Parameters assessed & $\begin{array}{l}\text { Weight } \\
\text { factor }\end{array}$ & $\begin{array}{l}1 \\
\text { (poor) }\end{array}$ & $\begin{array}{l}2 \\
\text { (average) }\end{array}$ & $\begin{array}{l}3 \text { (above } \\
\text { average) }\end{array}$ & $\begin{array}{l}4 \\
\text { (good) }\end{array}$ & $\begin{array}{l}5 \\
\text { (excellent) }\end{array}$ & $\begin{array}{l}\text { Total } \\
\text { possible }\end{array}$ & $\begin{array}{l}\text { Total } \\
\text { computed }\end{array}$ & Comments \\
\hline $\begin{array}{l}\text { Compliance with process } \\
\text { design criteria }\end{array}$ & 10 & & & 3 & & & 50 & 30 & $\begin{array}{l}\text { No match lines designating boundaries } \\
\text { indicated on PFD drawings }\end{array}$ \\
\hline $\begin{array}{l}\text { Document properly } \\
\text { authenticated }\end{array}$ & 7 & & & 3 & & & 35 & 21 & $\begin{array}{l}\text { Document not properly authenticated, no } \\
\text { permit number }\end{array}$ \\
\hline $\begin{array}{l}\text { Mass values for input \& } \\
\text { output shown }\end{array}$ & 10 & 1 & & & & & 50 & 10 & $\begin{array}{l}\text { No mass values provided on block process } \\
\text { flow diagram }\end{array}$ \\
\hline $\begin{array}{l}\text { Revisions } \\
\text { correctly shown }\end{array}$ & 5 & & & & & 5 & 25 & 25 & \\
\hline $\begin{array}{l}\text { Input \& output stream labels } \\
\text { properly defined }\end{array}$ & 10 & & 2 & & & & 50 & 20 & $\begin{array}{l}\text { Flow arrows inconsistent with PFD and P\&ID, } \\
\text { Fluid streams improperly defined. }\end{array}$ \\
\hline \multicolumn{7}{|l|}{ SUMMARY OF SCORING } & 230 & 84 & Score percentage $=50 \%$ \\
\hline
\end{tabular}

Table 1: PROCESS BLOCK FLOW DIAGRAM CHECK LIST (hypothetical sample). 
Citation: Facey R, Ouseph C (2012) Gate Review as a Project Management Tool for Optimal Outcome A Hypothetical Case Study. J Civil Environ Eng 2:119. doi:10.4172/2165-784X.1000119

Page 5 of 6

- Pipe Specification HOLD for missing general notes

The table 4 details the levels of criticalness of the documents with missing information identified above. From examination of the table below it can be seen that a majority of the documents are critical at the IFC stage to avoid delays in schedule related to contractor bidding, procurement, fabrication, construction, installation and start-up.

\section{Conclusion}

In summary, the following steps would help in the optimal management and completion of all stages in a project, all on schedule and within budget. Such steps generally include at a minimum the following:

- Develop a flow diagram incorporating all the tasks, phases, and time lines based on what is contained in the project/RFP reports and other contract \& contract related documents.
- Have the above diagram arranged in a PERT chart with critical steps identified for CPM analysis.

- Develop a detailed check list incorporating all parameters that are important to assess the suitability of each stage.

- As early as the conceptual stage and DBM phase, have HAZOP team from all applicable disciplines assembled for completing the HAZOP study.

- Ensure that those developing the check list and doing the scoring \& ranking have adequate prior experience or are doing under the immediate direction and guidance of those with substantial experience in the management of similar projects.

- The checklist scoring and ranking are subjective and therefore when completed, they must be peer reviewed for relevancy and consistency.

\section{GATE REVIEW: Construction drawings}

\begin{tabular}{|c|c|c|c|c|c|c|c|c|c|}
\hline Parameters assessed & Weight factor & 1 (poor) & 2 (average) & 3 (above average) & 4 (good) & 5 (excellent) & Total possible & Total computed & Comments \\
\hline $\begin{array}{l}\text { Compliance with process } \\
\text { flow diagram }\end{array}$ & 10 & & & & & 5 & 50 & 50 & \\
\hline $\begin{array}{l}\text { Project legal description } \\
\text { provided }\end{array}$ & 5 & & & & & 5 & 25 & 25 & \\
\hline Revisions correctly shown & 5 & & & & & 5 & 25 & 25 & \\
\hline Stream fluid title provided & 10 & 1 & & & & & 50 & 10 & $\begin{array}{l}\text { Not } \\
\text { indicated }\end{array}$ \\
\hline $\begin{array}{l}\text { Stream vapour mole } \\
\text { fraction shown }\end{array}$ & 10 & & & & & 5 & 50 & 50 & \\
\hline \multicolumn{7}{|l|}{ SUMMARY OF SCORING } & 250 & 160 & $\begin{array}{l}\text { Score percentage } \\
=64 \%\end{array}$ \\
\hline
\end{tabular}

Table 2: PROCESS HEAT \& MASS BALANCE CHECK LIST (hypothetical sample).

\begin{tabular}{|l|l|l|l|}
\hline Item & Deliverable & \multicolumn{1}{|c|}{ Level of Criticalness } & High \\
\hline 1 & Civil/Structural/Architectural Construction Work Packages & Moderate \\
\hline 2 & Site Utilities Plan & \\
\hline 3 & Equipment Data Sheets & \\
\hline 4 & Building Data Sheet & \\
\hline 5 & Shutdown Key & \\
\hline 6 & Control Philosophy & \\
\hline 7 & Instrument Index & \\
\hline 8 & Voltage Motor Schematic & \\
\hline 9 & Electrical Data Sheets & \\
\hline 10 & Electrical Construction Work Packages & \\
\hline 11 & Mechanical; Construction Work Packages & \\
\hline
\end{tabular}

Table 3: Levels of Criticalness for Key Missing Construction Drawings \& Documents.

\begin{tabular}{|l|l|l|l|}
\hline Item & Deliverable & \multicolumn{2}{c|}{ Level of Criticalness } \\
\hline 1 & Process P\&IDs & High & Loderate \\
\hline 2 & Utility P\&ID & & \\
\hline 3 & Line List & & \\
\hline 4 & Instrument Data Sheets & & \\
\hline 5 & Equipment Index & & \\
\hline 6 & Pipe Specification & & \\
\hline
\end{tabular}

Notes:

Red: High, missing document - significantly delay procurement, fabrication and construction. Yellow: Moderate, missing document - may delay procurement, fabrication and construction

Green: Low, missing document can be completed following completion of construction drawing without delay in procurement, fabrication and construction

Table 4: Levels of Criticalness for Construction Drawings \& Documents Missing Key. 


\section{Disclaimer}

This report written as a White Paper highlights certain deficiencies and limitations in the way Gate Reviews are often conducted. To minimize deficiencies and to achieve a higher level of accuracy in the gate review process, certain recommended solutions have been indicated and thereby to better execute the gate review process for the optimal management of projects. Any use or reliance of information contained in this report by any third party does so at their own peril and with the understanding that neither Gemini Corporation nor its employees accept responsibility for any damages suffered by any as a result of decisions made or actions taken based on this report. 